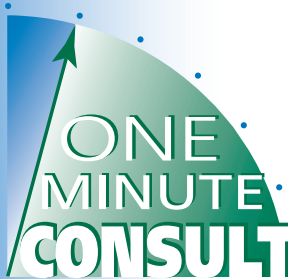

YUQING GAO, MD

Department of Medicine, Wayne State University

School of Medicine, Detroit, MI
AYMAN O. SOUBANI, MD

Division of Pulmonary, Critical Care, and Sleep

Medicine, Wayne State University School of Medicine; Professor of Medicine, Wayne State University School of Medicine; Medical Director Medical ICU, Harper University Hospital; Service Chief, Pulmonary and Critical Care, and Medical Director, Critical Care Service, Karmanos Cancer Center, Detroit, Ml

\title{
Q: What are the risks to inpatients during hospital construction or renovation?
}

\begin{abstract}
A: Hospital-acquired infections related to construction and renovation activities account for more than 5,000 deaths per year across the United States. ${ }^{1}$

Hospital construction, renovation, and demolition projects ultimately serve the interests of patients, but they also can put inpatients at risk of mold infection, Legionnaires disease, sleep deprivation, exacerbation of lung disease, and in rare cases, physical injury.

Hospitals are in a continuous state of transformation to meet the needs of medical and technologic advances and an increasing patient population, ${ }^{1}$ and in the last 10 years, more than $\$ 200$ billion has been spent on construction projects at US healthcare facilities. Therefore, constant attention is needed to reduce the risks to the health of hospitalized patients during these projects.
\end{abstract}

Even small concentrations of Aspergillus may cause infection in high-risk patients

\section{HOSPITAL-ACQUIRED INFECTIONS}

\section{Mold infections}

Construction can cause substantial dust contamination and scatter large amounts of fungal spores. An analysis conducted during a period of excavation at a hospital campus showed a significant association between excavation activities and hospital-acquired mold infections (hazard ratio $[\mathrm{HR}] 2.8, P=.01$ ) but not yeast infections (HR 0.75, $P=.78$ ). ${ }^{2}$

Aspergillus species have been the organisms most commonly involved in hospital-acquired mold infection. In a review of 53 studies including 458 patients, ${ }^{3}$ A fumigatus was identified in 154 patients, and A flawus was identified in 101 patients. A niger, A terreus, A nidulans, Zygomycetes, and other fungi were also identified, but to a much lesser extent. Hematologic

malignancies were the predominant underlying morbidity in 299 patients. Half of the sources of healthcare-associated Aspergillus outbreaks were estimated to result from construction and renovation activities within or surrounding the hospital. ${ }^{3}$

Heavy demolition and transportation of wreckage have been found to cause the greatest concentrations of Aspergillus species, ${ }^{1}$ but even small concentrations may be sufficient to cause infection in high-risk hospitalized patients. ${ }^{3}$ Invasive pulmonary aspergillosis is the mold infection most commonly associated with these activities, particularly in immunocompromised and critically ill patients. It is characterized by invasion of lung tissue by Aspergillus hyphae. Hematogenous dissemination occurs in about $25 \%$ of patients, and the death rate often exceeds $50 \%{ }^{4}$

A review of cases of fungal infection during hospital construction, renovation, and demolition projects from 1976 to 2014 identified 372 infected patients, of whom 180 died..$^{5}$ The majority of infections were due to Aspergillus. Other fungi included Rhizopus, Candida, and Fusarium. Infections occurred mainly in patients with hematologic malignancies and patients who had undergone stem cell transplant (76\%), followed by patients with other malignancies or transplant (19\%). Rarely affected were patients in the intensive care unit or patients with rheumatologic diseases or on hemodialysis. ${ }^{5}$

\section{Legionnaires disease}

Legionnaires disease is a form of atypical pneumonia caused by the bacterium Legionella, often associated with differing degrees of gastrointestinal symptoms. Legionella species are the bacteria most often associated with construction in hospitals, as construction and demolition often result in collections of stagnant water. 
The primary mode of transmission is inhalation of contaminated mist or aerosols. Legionella species can also colonize newly constructed hospital buildings within weeks of installation of water fixtures.

In a large university-affiliated hospital, 2 cases of nosocomial legionellosis were identified during a period of major construction. ${ }^{6}$ An epidemiologic investigation traced the source to a widespread contamination of potable water within the hospital. One patient's isolate was similar to that of a water sample from the faucet in his room, and an association between Legionnaires disease and construction was postulated.

Another institution's newly constructed hematology-oncology unit identified 10 cases of Legionnaires disease over a 12-week period in patients and visitors with exposure to the unit during and within the incubation period. ${ }^{7}$ A clinical and environmental assessment found 3 clinical isolates of Legionella identical to environmental isolates found from the unit, strongly implicating the potable water system as the likely source. ${ }^{?}$

In Ohio, 11 cases of hospital-acquired Legionnaires disease were identified in patients moved to a newly constructed 12-story addition to a hospital, and 1 of those died. ${ }^{8}$

Legionella infections appear to be less common than mold infections when reviewing the available literature on patients exposed to hospital construction, renovation, or demolition activities. Yet unlike mold infections, which occur mostly in immunocompromised patients, Legionella also affects people with normal immunity. ${ }^{1}$

\section{NONCOMMUNICABLE ILLNESSES}

\section{Sleep deprivation}

Noise in hospitals has been linked to sleep disturbances in inpatients. A study using noise dosimeters in a university hospital found a mean continuous noise level of $63.5 \mathrm{dBA}$ (Aweighting of decibels indicates risk of hearing loss) over a 24-hour period, a level more than 2 times higher than the recommended 30 dBA. ${ }^{9}$ The same study also found a significant correlation between sleep disturbance in inpatients and increasing noise levels, in a doseresponse manner.
Common sources of noise during construction may include power generators, welding and cutting equipment, and transport of materials. While construction activities themselves have yet to be directly linked to sleep deprivation in patients, construction is inevitably accompanied by noise.

Noise is the most common factor interfering with sleep reported by hospitalized patients. Other effects of noise on patients include a rise in heart rate and blood pressure, increased cholesterol and triglyceride levels, increased use of sedatives, and longer length of stay. ${ }^{9,10}$ Although construction is rarely done at night, patients generally take naps during the day, so the noise is disruptive.

\section{Physical injuries}

Hospitalized patients rarely suffer injuries related to hospital construction. However, these incidents may be underreported. Few cases of physical injury in patients exposed to construction or renovation in healthcare facilities can be found through a Web search..$^{11,12}$

\section{Exacerbation of lung disease}

Inhalation of indoor air pollutants exposed during renovation can directly trigger an inflammatory response and cause exacerbation in patients with chronic lung diseases such as asthma and chronic obstructive pulmonary disease. No study has specifically examined the effect of hospital construction or renovation on exacerbation of chronic lung diseases in hospitalized patients. Nevertheless, dust and indoor air pollutants from building renovation have often been reported as agents associated with work-related asthma. ${ }^{13}$

\section{THE MESSAGE}

Although the risks to inpatients during hospital construction projects appear minimal, their effect can at times be detrimental, especially to the immunocompromised. Hospitals should adhere to infection control risk assessment protocols during construction events. The small number of outbreaks of construction-related infections can make the diagnosis of nosocomial origin of these infections challenging; a high index of suspicion is needed.

Currently in the United States, there is no standard regarding acceptable levels of air-

\section{Noise is the most common factor interfering with sleep reported by hospitalized patients}


borne mold concentrations, and data to support routine hospital air sampling or validation of available air samplers are inadequate. This remains an area for future research. ${ }^{14,15}$

Certain measures have been shown to significantly decrease the risk of mold infections and other nosocomial infections during construction projects, including ${ }^{16}$ :

- Effective dust control through containment units and barriers

- Consistent use of high-efficiency particulate air filters in hospital units that care for immunocompromised and critically ill patients

- Routine surveillance.
Noise and vibration can be reduced by temporary walls and careful tool selection and scheduling. Similarly, temporary walls and other barriers help protect healthcare employees and patients from the risk of direct physical injury.

Preconstruction risk assessments that address infection control, safety, noise, and air quality are crucial, and the Joint Commission generally requires such assessments. Further, education of hospital staff and members of the construction team about the potential detrimental effects of hospital construction and renovation is essential to secure a safe environment.

\section{REFERENCES}

1. Clair JD, Colatrella S. Opening Pandora's (tool) box: health care construction and associated risk for nosocomial infection. Infect Disord Drug Targets 2013; 13(3):177-183. pmid:23961740

2. Pokala HR, Leonard D, Cox J, et al. Association of hospital construction with the development of healthcare associated environmental mold infections (HAEMI) in pediatric patients with leukemia. Pediatr Blood Cancer 2014; 61(2):276-280. doi:10.1002/pbc.24685

3. Vonberg RP, Gastmeier P. Nosocomial aspergillosis in outbreak settings. J Hosp Infect 2006; 63(3):246-254. doi:10.1016/j.jhin.2006.02.014

4. Kanj A, Abdallah N, Soubani AO. The spectrum of pulmonary aspergillosis. Respir Med 2018; 141:121-131. doi:10.1016/j.rmed.2018.06.029

5. Kanamori H, Rutala WA, Sickbert-Bennett EE, Weber DJ. Review of fungal outbreaks and infection prevention in healthcare settings during construction and renovation. Clin Infect Dis 2015; 61(3):433444. doi:10.1093/cid/civ297

6. Perola O, Kauppinen J, Kusnetsov J, Heikkinen J, Jokinen C, Katila ML. Nosocomial Legionella pneumophila serogroup 5 outbreak associated with persistent colonization of a hospital water system. APMIS 2002: 110(12):863-868. pmid:12645664

7. Francois Watkins LK, Toews KE, Harris AM, et al. Lessons from an outbreak of Legionnaires disease on a hematology-oncology unit. Infect Control Hosp Epidemiol 2017; 38(3):306-313. doi:10.1017/ice.2016.281

8. Lin YE, Stout JE, Yu VL. Prevention of hospital-acquired legionellosis. Curr Opin Infect Dis 2011; 24(4):350-356. doi:10.1097/QCO.0b013e3283486c6e

9. Park MJ, Yoo JH, Cho BW, Kim KT, Jeong WC, Ha M. Noise in hospital rooms and sleep disturbance in hospitalized medical patients.
Environ Health Toxicol 2014; 29:e2014006. doi:10.5620/eht.2014.29.e2014006

10. Buxton OM, Ellenbogen JM, Wang W, et al. Sleep disruption due to hospital noises: a prospective evaluation. Ann Intern Med 2012; 157(3):170-179. doi:10.7326/0003-4819-157-3-201208070-00472

11. Heldt D; The Gazette. Accident will delay University of lowa Hospitals construction work for several days. https://www.thegazette. com/2013/03/08/university-of-iowa-hospitals-patient-injured-byfalling-construction-debris. Accessed July 22, 2019.

12. Darrah N; Fox News. Texas hospital explosion kills 1, leaves 12 injured. https://www.foxnews.com/us/texas-hospital-explosion-kills1-leaves-12-injured. Accessed July 22, 2019.

13. Centers for Disease Control and Prevention (CDC). Work-related asthma: most frequently reported agents associated with workrelated asthma cases by state, 2009-2012. https://wwwn.cdc.gov/ eworld/Data/926. Accessed July 22, 2019.

14. Patterson TF, Thompson GR 3rd, Denning DW, et al. Practice guidelines for the diagnosis and management of Aspergillosis: 2016 update by the Infectious Diseases Society of America. Clin Infect Dis 2016; 63(4):e1-e60. doi:10.1093/cid/ciw326

15. Chang CC, Athan E, Morrissey CO, Slavin MA. Preventing invasive fungal infection during hospital building works. Intern Med J 2008; 38(6b):538-541. doi:10.1111/j.1445-5994.2008.01727.x

16. Oren I, Haddad N, Finkelstein R, Rowe JM. Invasive pulmonary aspergillosis in neutropenic patients during hospital construction: before and after chemoprophylaxis and institution of HEPA filters. Am J Hematol 2001; 66(4):257-262. doi:10.1002/ajh.1054

ADDRESS: Ayman O. Soubani, MD, Wayne State University School of Medicine, 3990 John R-3 Hudson, Detroit, MI 48201;

asoubani@med.wayne.edu 